DIAS, L.R.O. et al. Fundamentos da exploração ecográfica. Parte I: Princípios biofísicos. PUBVET, Londrina, V. 8, N. 4, Ed. 253, Art. 1676, Fevereiro, 2014.

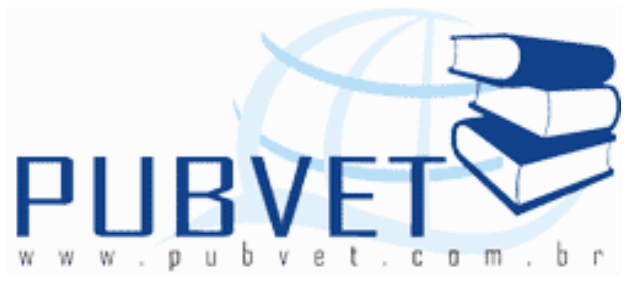

PUBVET, Publicações em Medicina Veterinária e Zootecnia.

\title{
Fundamentos da exploração ecográfica \\ Parte I: Princípios biofísicos
}

\section{Luzia Renata Oliveira Dias ${ }^{1}$, Regis Leal Lima², Marco Antônio de Oliveira Viu ${ }^{3}$, Alessandra Feijó Marcondes Viu ${ }^{3}$, Dyomar Toledo Lopes ${ }^{3}$}

${ }^{1}$ Médica Veterinária Residente do Laboratório de Fisiopatologia da Reprodução Animal, UFG/CAJ. e-mail: Ir_dias@hotmail.com

2 Médico Veterinário colaborador do Laboratório de Fisiopatologia da Reprodução Animal, UFG/CAJ.

${ }^{3}$ Professores da Universidade Federal de Goiás - UFG. Campus Jataí.

\section{Resumo}

A ecografia é um método de obtenção de imagens através de pulsos sonoros, operados em frequências de um a vinte $\mathrm{MHz}$, transmitidos para dentro do organismo que são refletidos em forma de eco. Além de ser uma técnica com ausência de radiação ionizante permite a avaliação em tempo real. Uma onda de ultrassom é uma forma de energia acústica, gerada quando vários cristais piezoelétricos no interior de um transdutor vibram a uma frequência elevada. O exame tridimensional fundamenta-se na reconstrução digital de uma imagem bidimensional adquirida por meio de transdutores multifrequenciais comuns. A otimização de imagens em escala de cinza pode ser obtida através de ajustes na vazão de potência, ganho, zona focal, campo de visão, densidade de linhas, curvas da escala de cinza, alcance dinâmico e 
DIAS, L.R.O. et al. Fundamentos da exploração ecográfica. Parte I: Princípios biofísicos. PUBVET, Londrina, V. 8, N. 4, Ed. 253, Art. 1676, Fevereiro, 2014.

persistência. A ferramenta Doppler associada à ultrassonografia convencional proporciona informações em tempo real sobre a arquitetura vascular e os aspectos hemodinâmicos dos vasos em diversos órgãos, podendo ser demonstrada através do Doppler pulsátil, colorido e Doppler de potência. Desta forma, objetivou-se com o presente estudo revisar os princípios biofísicos da exploração ecográfica, uma vez que são de fundamental relevância para o auxílio diagnóstico na Medicina Veterinária.

Palavras-chave: Cristais piezoelétricos, Doppler, ecografia, ultrassom

\title{
Fundamentals of ultrasound exploration \\ Part I: Biophysical principles
}

\begin{abstract}
Ultrasound is a method of obtaining images by sound pulses operated at frequencies from one to twenty $\mathrm{MHz}$, conveyed into the body that are reflected in the form of an echo. Besides being a technique with no ionizing radiation allows real-time assessment. An ultrasound wave is a form of acoustic energy generated when multiple piezoelectric crystals vibrate into a transducer at a high frequency. The examination is based on three-dimensional digital reconstruction of a two-dimensional image acquired through common multifrequency transducer. Optimizing images in grayscale can be obtained by adjusting the flow of power, gain, focal zone, field of view, density of lines, curves, gray scale, dynamic range and persistence. The tool Doppler associated with conventional ultrasound provides real-time information on the vascular architecture and hemodynamic aspects of vessels in several organs and can be demonstrated by pulsed Doppler, color Doppler and power Doppler. Thus, the aim with this study was to review the biophysical principles of ultrasound scanning, since they are of fundamental importance for the diagnostic aid in veterinary medicine.
\end{abstract}

Keywords: Doppler, echography, piezoelectric crystals, ultrasound 
DIAS, L.R.O. et al. Fundamentos da exploração ecográfica. Parte I: Princípios biofísicos. PUBVET, Londrina, V. 8, N. 4, Ed. 253, Art. 1676, Fevereiro, 2014.

\section{INTRODUÇÃO}

A ecografia é um método de obtenção de imagens através de pulsos sonoros operados em frequências de um a vinte $\mathrm{MHz}$, transmitidos para dentro do organismo e que são refletidos em forma de eco. Além de ser uma técnica com ausência de radiação ionizante permite a avaliação em tempo real, como o exame de estruturas em movimento e possibilita a aquisição de imagens multiplanares (MIDDLETON et al., 2005).

De acordo com CRUZ \& FREITAS (2001), esta técnica de diagnóstico por imagem é muito utilizada na Medicina Veterinária, pois se realizada de forma dinâmica auxilia na identificação das condições fisiológicas e patológicas dos órgãos examinados. No entanto, segundo VESCOVI et al. (2009), apesar de apresentar benefícios abundantes a ecografia exibe divergência na interpretação de seus achados, devido à análise subjetiva e individual, o que torna relevante a aplicação de métodos que quantifiquem a ecogenicidade e ecotextura.

O conhecimento dos fundamentos físicos e tecnológicos relacionados com a formação das imagens torna-se imprescindível, uma vez que proporciona uma correta interpretação diagnóstica (CHAMMAS \& CERRI, 2009). Além disso, ressalta-se a importância do conhecimento amplo dos métodos modernos empregados na ecografia, como aquisição de imagens tridimensionais, a sonografia pelo Doppler e sua otimização, visando a máxima exploração do potencial destes. Desta forma, objetivou-se com este estudo revisar os princípios biofísicos da exploração ecográfica, uma vez que são de fundamental relevância para o auxílio diagnóstico na Medicina Veterinária.

\section{Base Biofísica}

Uma onda de ultrassom é uma forma de energia acústica, gerada quando vários cristais piezoelétricos (do grego piézo: comprimir, e electrico: eletricidade) no interior de um transdutor vibram a uma frequência elevada, em resposta a uma corrente alternada, produzindo assim imagens (Figura 1). As ondas acústicas são ondas de pressão, refletidas pela compressão e 
DIAS, L.R.O. et al. Fundamentos da exploração ecográfica. Parte I: Princípios biofísicos. PUBVET, Londrina, V. 8, N. 4, Ed. 253, Art. 1676, Fevereiro, 2014.

descompressão (rarefação) alternadas das moléculas dos tecidos examinados. Cada onda é caracterizada por um comprimento de onda específico (distância entre picos de pressão) e por uma frequência (número de picos de pressão por segundo), demonstrados na Figura 2. A frequência é determinada pela fonte do som e não apenas pelo meio em que o som passa (ALDRICH, 2007; SITES et al., 2007).

O som é uma onda mecânica que se propaga pela vibração das partículas do meio no qual se alastra. Ultrassom é um termo que se aplica à onda sonora cuja frequência é superior à de $20 \mathrm{KHz}$, que é o limite da audição humana (CARVALHO, 2004).

A velocidade de propagação é aquela em que o som pode viajar através de um meio, geralmente considerado $1,540 \mathrm{~m} / \mathrm{s}$ para o tecido macio. O que determina essa velocidade são as propriedades do meio, principalmente densidade e rigidez, mas razoavelmente ela se apresenta constante (ALDRICH, 2007).

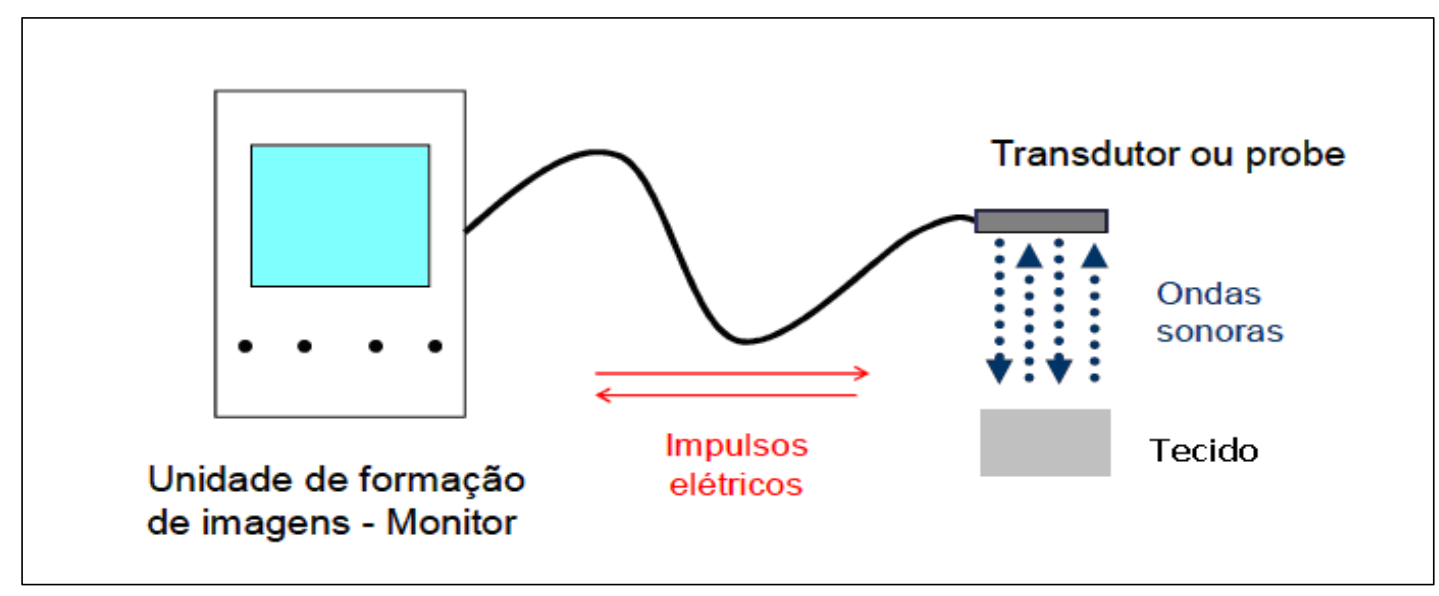

FIGURA 1 - Esquema de funcionamento do aparelho ultrassonográfico.

Fonte: adaptado de FERNANDES (2012). 
DIAS, L.R.O. et al. Fundamentos da exploração ecográfica. Parte I: Princípios biofísicos. PUBVET, Londrina, V. 8, N. 4, Ed. 253, Art. 1676, Fevereiro, 2014.

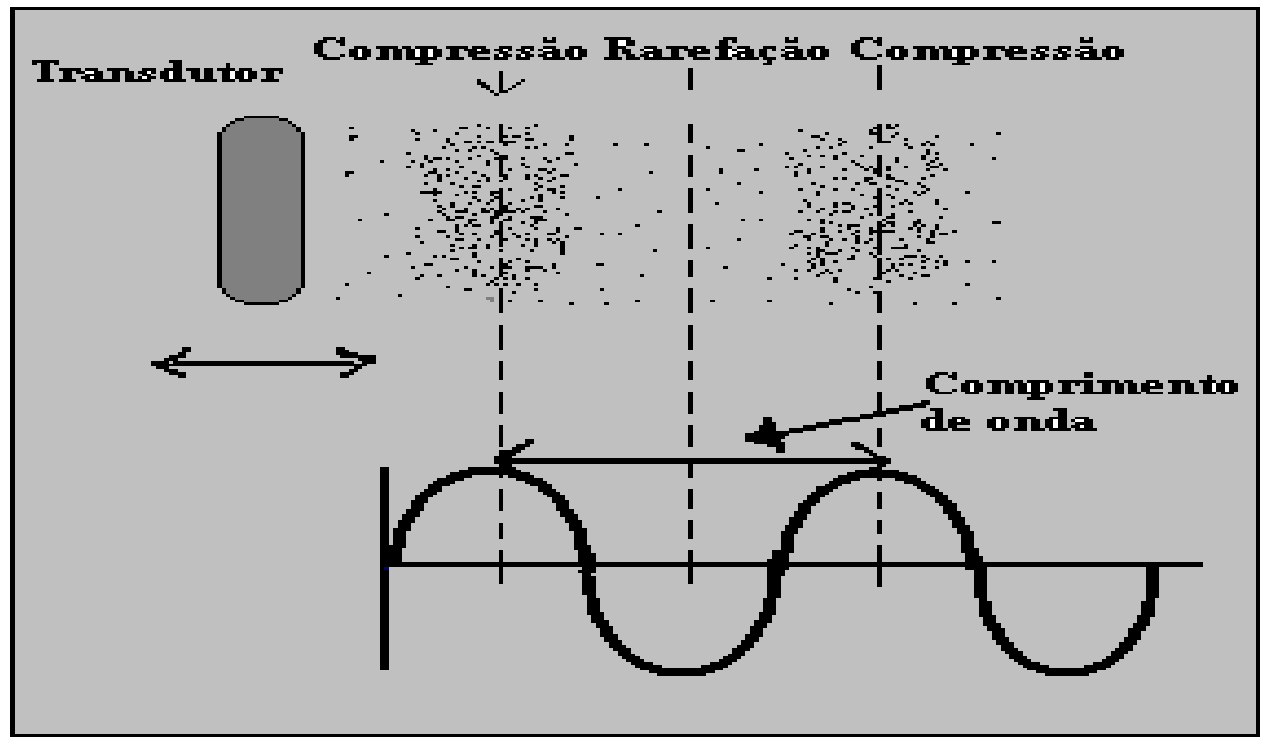

FIGURA 2 - A figura descreve a energia acústica (feixe de ultrassom) movendo-se através de ondas longitudinais. Estas ondas sonoras correspondem à compressão periódica e rarefação do meio em que se movem. O comprimento de onda também é demonstrado.

Fonte: adaptado de VARGAS et al. (2008).

Segundo MIDDLETON et al. (2005), a intensidade do feixe de ultrassom é reduzida pela atenuação devido à vários processos como a reflexão, refração, espalhamento e absorção. A quantidade de atenuação varia com a frequência de ultrassom.

De acordo com SITES et al. (2007), a reflexão ou dispersão retrógrada acontece quando o pulso encontra uma interface entre dois tecidos que têm impedância acústica diferente (produto entre a velocidade do som e a densidade do tecido). Quanto maior a impedância acústica, maior a dispersão ou os reflexos retrógrados.

Os refletores especulares (grandes interfaces lisas) orientados perpendicularmente à direção do pulso transmitido irão refletir o som diretamente de volta aos elementos de cristal ativos no transdutor, produzindo um sinal forte. Ao contrário, quando não estão orientados perpendicularmente 
DIAS, L.R.O. et al. Fundamentos da exploração ecográfica. Parte I: Princípios biofísicos. PUBVET, Londrina, V. 8, N. 4, Ed. 253, Art. 1676, Fevereiro, 2014.

produzirão um sinal mais fraco. Assim, a dispersão indica o redirecionamento do som em múltiplas direções (ALDRICH, 2007).

Quando o som encontra uma interface entre dois tecidos que 0 transmitem em velocidades distintas ocorre mudança na direção do mesmo (impedância acústica alta entre os tecidos), indicando uma refração. A refração é importante por ser uma das causas de localização incorreta de uma estrutura numa imagem ecográfica. Já a absorção indica a perda de energia sonora secundária ou sua conversão em energia térmica. Quanto maior a densidade do tecido maior a absorção (COLTRERA, 2010).

\section{Instrumentação}

A ecografia se fundamenta no efeito piezoelétrico, no qual cristais de quartzo submetidos a correntes elétricas emitem ondas sonoras de alta frequência (MHz) (HAGEN, 2009). Materiais piezoelétricos têm a propriedade de que quando mecanicamente deformados produzem um campo elétrico que tenta restabelecer a forma. Inversamente, se um campo elétrico é aplicado a um material piezoelétrico na forma de um impulso de tensão o material será fisicamente deformado (ALDRICH, 2007). O efeito piezoelétrico é a capacidade que determinadas matérias, como cristais de quartzo, têm de vibrar em determinada frequência quando submetidos a uma pressão mecânica, como o som, transformando-a em impulsos elétricos (CARVALHO, 2004).

A produção de imagens no aparelho de ultrassom fundamenta-se em ondas sonoras de alta frequência. Estas ondas são emitidas pela vibração de cristais com propriedades piezoelétricas, presentes no transdutor do aparelho, quando submetidas a correntes elétricas alternadas, o que é ilustrado na Figura 3 (JAINUDEEN \& HAFEZ 2004). A imagem é formada a partir dos ecos que retornam dos tecidos ao transdutor após cada pulso (NYLAND \& MATTOON, 2004). O transdutor, após emitir a onda, muda para um modo de recepção (SITES et al., 2007). A ideia básica de formação de imagem utilizando ultrassom é de visualizar as ondas ultrassônicas refletidas em 
DIAS, L.R.O. et al. Fundamentos da exploração ecográfica. Parte I: Princípios biofísicos. PUBVET, Londrina, V. 8, N. 4, Ed. 253, Art. 1676, Fevereiro, 2014.

diferentes níveis de cinza. Essa técnica é conhecida como princípio pulso eco (KIMURA \& COSTA, 2007).

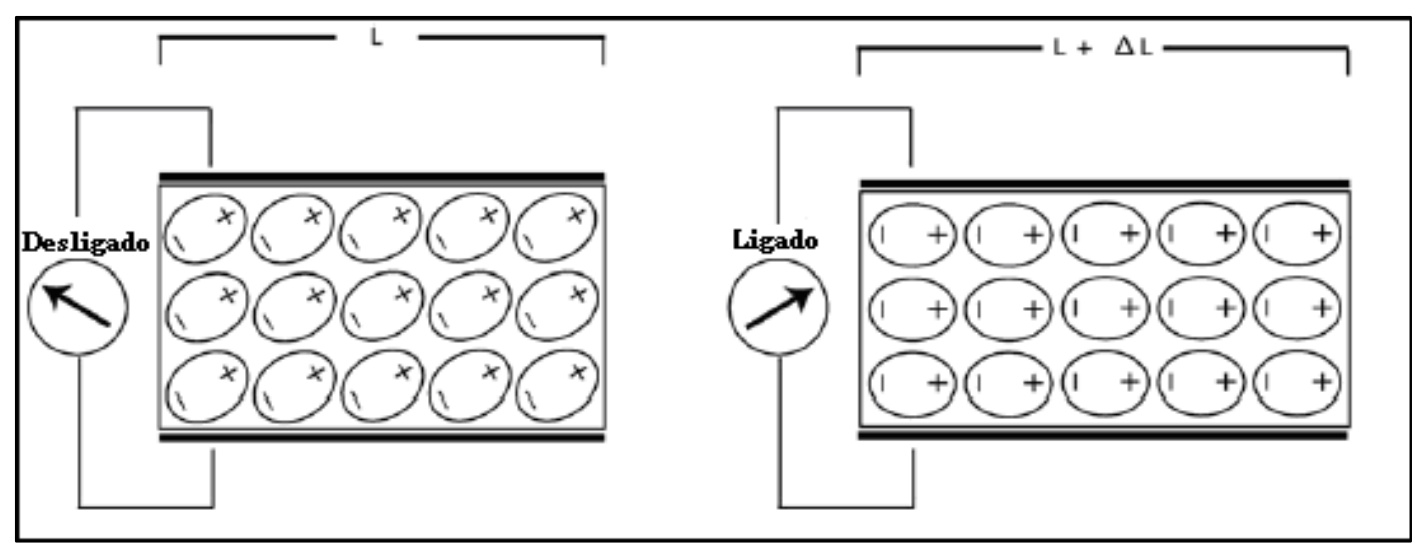

FIGURA 3 - A aplicação de uma tensão a um cristal piezoelétrico faz com que os elementos dipolares $(\mathrm{L}=$ tamanho original) se alinhem com o campo aplicado, alternando a forma do cristal, conduzindo a uma alteração do tamanho ( $\Delta \mathrm{L}=$ tamanho pós-expansão). A expansão repetida e contração do cristal geram as ondas sonoras. Por outro lado, a energia do som refletido pode alterar a forma de um pequeno cristal, induzindo à sincronização da variação de voltagem.

Fonte: adaptado de COLTRERA (2010).

Este processo de transmissão e recepção pode ser repetido até 10.000 vezes por segundo e, quando acoplado ao processamento do computador, resultará na geração de uma imagem em tempo real bidimensional que parece uniforme (SITES et al., 2007).

Essas ondas sonoras têm habilidade de se propagar através dos tecidos orgânicos. À medida que uma onda atravessa um determinado organismo, parte é refletida na forma de um eco e a outra parte segue agindo mutuamente com os tecidos mais profundos. O reflexo dessas ondas é processado por um conversor de exposição e lançado na tela do aparelho. Quanto maior a reflexão por parte do tecido, mais brilhantes são os pontos 
DIAS, L.R.O. et al. Fundamentos da exploração ecográfica. Parte I: Princípios biofísicos. PUBVET, Londrina, V. 8, N. 4, Ed. 253, Art. 1676, Fevereiro, 2014.

formados (CARVALHO, 2004; JAINUDEEN \& HAFEZ 2004). A velocidade de propagação é independente da frequência, mas depende das características dos tecidos visualizados (CHAMMAS \& CERRI, 2009).

A força que essas ondas retornam ao transdutor e o tempo que elas são recebidas afetam a intensidade e a posição da imagem que aparece no monitor (FERNANDES, 2012).

As imagens aparecem de várias formas na tela do aparelho, cada uma de acordo com a constituição do tecido, como por exemplo, a imagem hiperecoica exibe estruturas brilhantes, altamente reflexivas, prevalecendo o branco, enquanto a imagem hipoecoica reproduz ecos difundidos e reflexão intermediária. A imagem anecoica ocorre na inexistência de ecos, o que é típico de estruturas líquidas que aparecem como imagens negras no monitor (NEVES et al., 2008).

De acordo com COLTRERA (2010), o tamanho e a configuração do pulso sonoro transmitido determinam a resolução da imagem, considerada em três dimensões (Figura 4). A resolução axial é medida ao longo da direção do pulso sonoro. Sondas de frequência mais alta produzem melhor resolução axial. Porém, essas sondas são úteis somente em estruturas superficiais, pois o som de alta frequência não penetra profundamente nos tecidos. A resolução lateral designa a capacidade de resolução de objetos localizados lado a lado, perpendicularmente ao feixe sonoro. Já a resolução em elevação indica capacidade de resolução de objetos que estejam na mesma distância em relação ao transdutor, mas estão localizados perpendicularmente ao plano de aquisição de imagens.

De acordo com SITES et al. (2007), a zona focal representa a parte mais estreita do feixe sonoro, devendo ser posicionada no nível de interesse.

Segundo FERNANDES (2012), quatro modelos de imagem ecográficas podem ser utilizados, dentre os quais: modo- $A$, modo-B, modo-M e o Doppler.

O modo-A "modo de amplitude", produz uma imagem unidimensional, fornecendo a amplitude e a profundidade das ondas no tecido 
DIAS, L.R.O. et al. Fundamentos da exploração ecográfica. Parte I: Princípios biofísicos. PUBVET, Londrina, V. 8, N. 4, Ed. 253, Art. 1676, Fevereiro, 2014.

(CARVALHO, 2004). Segundo CHAMMAS \& CERRI (2009), a amplitude é a intensidade ou magnitude da onda sonora.

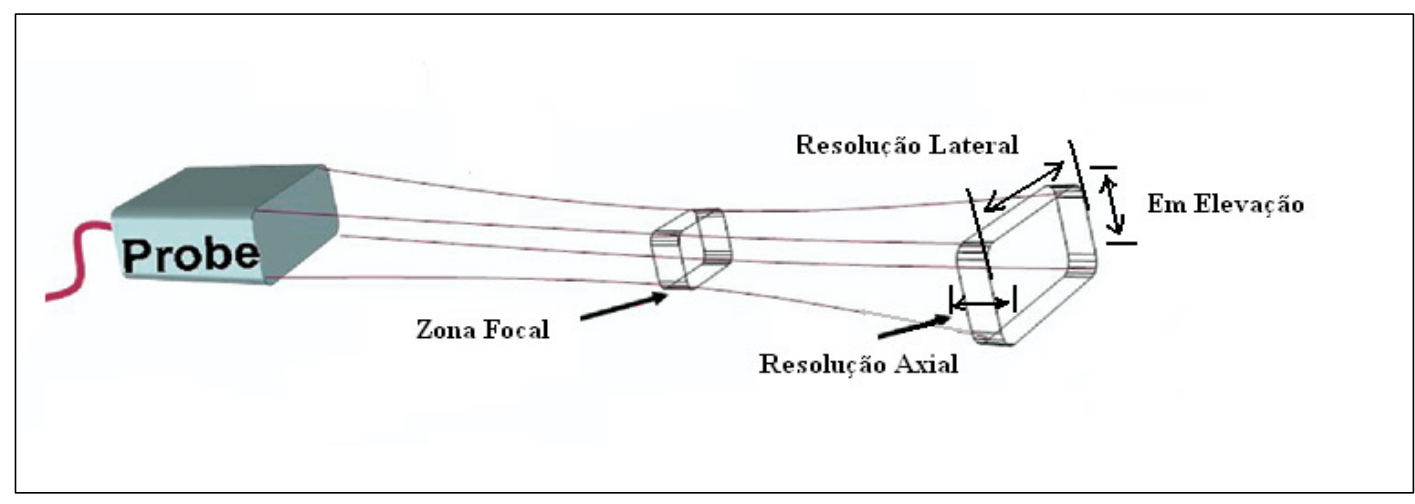

FIGURA 4 - Este esquema mostra um feixe sonoro produzido por uma sonda. No nível da zona focal o feixe é mais estreito. A resolução em elevação é equivalente à espessura do corte e depende da forma dos elementos de cristal do transdutor. A resolução axial depende da frequência transmitida e melhora com sondas de frequência mais alta.

Fonte: Adaptado de SITES et al. (2007).

O modo-B produz uma imagem bidimensional em tempo real $\mathrm{e}$ consiste de um conjunto de ecos ultrassonográficos dispostos em um plano lado a lado. A imagem é constituída por um ciclo completo de emissão e recepção de um conjunto de feixes acústicos e a percepção visual do operador é a de uma imagem em movimento (SIMÕES, 2008).

O modo-M, utilizado para a obtenção de imagens de alta resolução, pode ser classificado como uma adaptação do modo-B. É usado principalmente para avaliar estruturas de órgãos em movimento, como o coração (FERNANDES, 2012).

O modo Doppler fornece informações instantâneas sobre a arquitetura vascular e os aspectos hemodinâmicos dos vasos sanguíneos, 
DIAS, L.R.O. et al. Fundamentos da exploração ecográfica. Parte I: Princípios biofísicos. PUBVET, Londrina, V. 8, N. 4, Ed. 253, Art. 1676, Fevereiro, 2014.

permitindo determinar a presença, a direção e o tipo de fluxo sanguíneo (CARVALHO et al., 2008). Este modo será discutido mais adiante.

$\mathrm{Na}$ composição em tempo real o som é dirigido em múltiplos ângulos, assim como perpendicularmente. A média dos sinais que se originam a ângulos diferentes resulta, teoricamente, em acentuar os refletores de alto nível e retirar a ênfase dos refletores fracos e do ruído. Como resultado final obtém-se uma melhora da razão sinal-ruído e do contraste tecidual. Porém, na ecografia em tempo real o campo de visão é limitado quando se utiliza transdutores em arranjo linear de alta resolução. No entanto, uma técnica de captação de posição baseada no registro de imagens permite a geração de imagens panorâmicas em tempo real, sem nenhuma perda da resolução (MIDDLETON et al., 2005).

De acordo com ALDRICH (2007), o termo tempo real se refere à capacidade do aparelho de ultrassom para exibir uma sequência rápida de várias digitalizações em modo $B$ de tais imagens onde qualquer movimento é visualizado como realmente ocorre. Geralmente entre 15 e 60 quadros de imagem por segundo podem ser mostrados no equipamento moderno. É interessante notar que à medida que o número de quadros mostrados por segundo (a velocidade de enquadramento) é aumentada, mais suave é o aparecimento de qualquer movimento. Para produzir o efeito de movimento contínuo, 16 quadros por segundos precisam ser exibidos.

Os transdutores são como geradores, pois são capazes de transformar uma forma de energia em outra, transforma energia eletromagnética em mecânica e vice-versa. A frequência do transdutor é determinada pela onda de maior amplitude. São classificados de acordo com tipo de imagem produzida (KEALY \& MCALLISTER, 2005; DROST, 2007).

A frequência emitida por determinado transdutor depende das características dos cristais piezoelétricos especiais contidos nesse aparelho (NYLAND \& MATTOON, 2004), bem como da espessura do material piezoelétrico utilizado na sua construção (CARVALHO, 2004). Segundo HAGEN (2009), a emissão das ondas sonoras de determinado elemento piezoelétrico 
DIAS, L.R.O. et al. Fundamentos da exploração ecográfica. Parte I: Princípios biofísicos. PUBVET, Londrina, V. 8, N. 4, Ed. 253, Art. 1676, Fevereiro, 2014.

ocorre de maneira como se estivessem saindo de uma fonte puntiforme, com um feixe tridimensional se formando e que é constituído de um feixe primário e vários feixes secundários (Figura 5).

De acordo com LIEU (2010), nos transdutores de baixa frequência $(3,0$ a $3,5 \mathrm{MHz})$ as ondas sonoras penetram mais profundamente as estruturas, nos de frequência mais alta $(5,0$ a $7,5 \mathrm{MHz})$ penetram mais superficialmente.

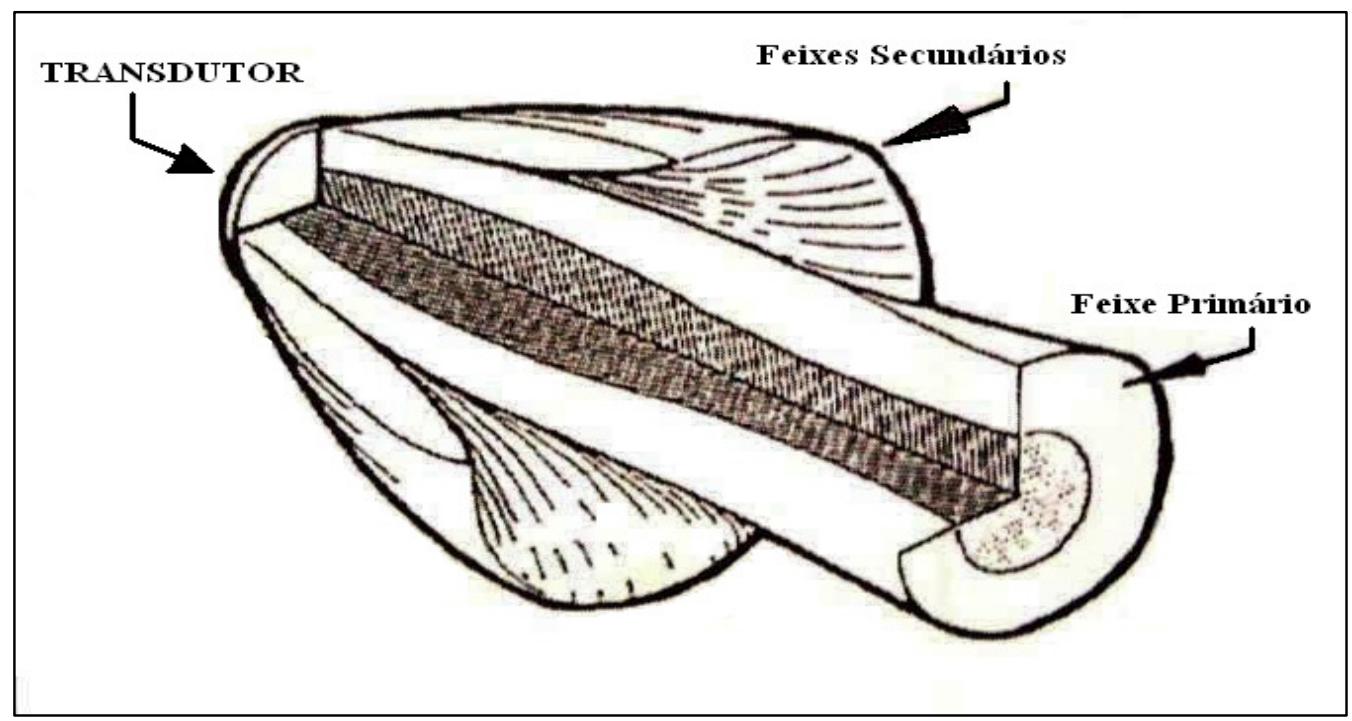

FIGURA 5 - Emissão das ondas sonoras do elemento piezoelétrico, transdutor, feixe primário e feixes secundários.

Fonte: adaptado de HAGEN (2009).

Os transdutores em tempo real são apresentados como transdutores mecânicos, em arranjo de múltiplos elementos, em arranjo de fase, em arranjo linear ou linear sequencial, em arranjo curvo, arranjo anular, arranjos bidimensionais e sondas intraluminares (MIDDLETON et al., 2005).

O transdutor mecânico setorial usa um único elemento piezoelétrico de grande tamanho para gerar e receber pulsos ultrassonográficos. Um movimento de oscilação e rotação do elemento de cristal direciona o feixe e a focalização é feita através desses elementos de formas diferentes. As desvantagens desse transdutor é que a zona focal é fixa e o movimento não é 
DIAS, L.R.O. et al. Fundamentos da exploração ecográfica. Parte I: Princípios biofísicos. PUBVET, Londrina, V. 8, N. 4, Ed. 253, Art. 1676, Fevereiro, 2014.

rápido o bastante para produzir imagens do Doppler colorido (FISCHETTI \& SCOTT, 2007; SANTANA, 2008).

Os transdutores de múltiplos elementos em grande parte substituíram os mecânicos setoriais. Estes possuem grupos de pequenos elementos de cristal dispostos sequencialmente. Esses arranjos podem fazer varredura em tempo real e ao mesmo tempo focalizar múltiplos níveis. A imagem criada por esses transdutores consiste em múltiplas linhas de varredura dispostas lado a lado (RUMACK et al., 2012).

No transdutor em arranjo de fase todos os elementos do arranjo participam da formação de cada pulso transmitido. A imagem produzida é em formato setorial (Figura 6), devido aos feixes sonoros serem dirigidos em ângulos variáveis de um lado ao outro do transdutor. A sonda é capaz de examinar áreas como entre as costelas, onde o acesso acústico é limitado. Esses arranjos têm um pequeno campo de visão superficial e uma deficiência de focalização próxima e também na periférica. Porém, são bons para aquisição de imagens profundas em modo Doppler (NYLAND \& MATTOON, 2004; MIDDLETON et al., 2005; ALDRICH, 2007).

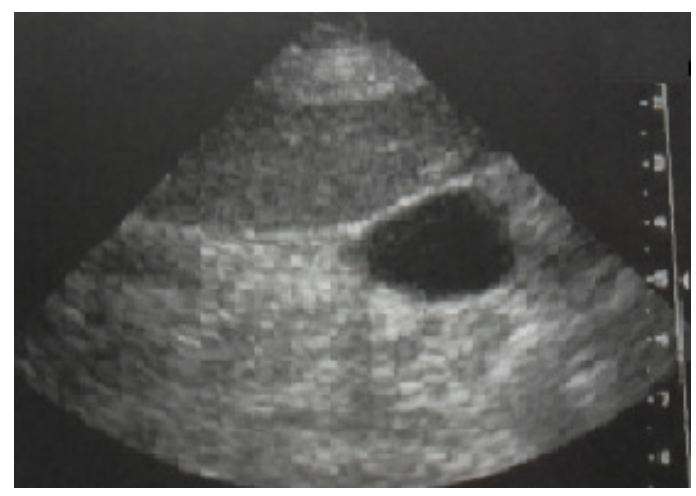

FIGURA 6 - Imagem da vesícula biliar e do fígado. Transdutor em arranjo de fase mostrando um formato setorial.

Fonte: Adaptado de MIDDLETON et al. (2005).

Os arranjos lineares, ao contrário dos de fase, ativam um grupo limitado de elementos adjacentes para gerar cada pulso, onde cada pulso 
DIAS, L.R.O. et al. Fundamentos da exploração ecográfica. Parte I: Princípios biofísicos. PUBVET, Londrina, V. 8, N. 4, Ed. 253, Art. 1676, Fevereiro, 2014.

percorre a mesma direção (simples varredura), estando orientados perpendicularmente à superfície do transdutor. A imagem produzida é retangular, mas uma imagem trapezoide pode ser originada conforme a direção dos pulsos seja manipulada (Figura 7). Esses arranjos apresentam elevada resolução no campo próximo e grande campo de visão superficial. No entanto, o grande tamanho do arranjo linear restringe seu uso em áreas de acesso limitado, além de seu limitado campo de visão em profundidade (NYLAND \& MATTOON, 2004; ALDRICH, 2007).

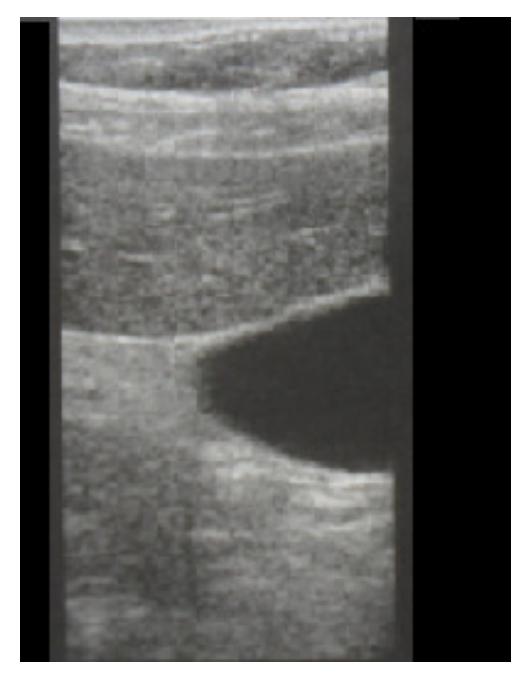

FIGURA 7 - Imagem da vesícula biliar e do fígado. Transdutor em arranjo linear mostrando um formato retangular.

Fonte: Adaptado de MIDDLETON et al. (2005).

Os arranjos curvos podem ser formados em diferentes formas e tamanhos. Quando se reformula uma superfície de arranjo linear para uma forma curva, uma imagem de forma setorial é produzida, com um ápice convexo (Figura 8). Assim, um campo de visão distante mais amplo é formado, mas a resolução da sonda é reduzida. Sondas com raio de curvatura curto podem ser usadas para exame endoluminar e as com raio de curvatura maior podem ser usadas para exames abdominais gerais e obstétricos (MIDDLETON et al., 2005; RUMACK et al., 2012). 
DIAS, L.R.O. et al. Fundamentos da exploração ecográfica. Parte I: Princípios biofísicos.

PUBVET, Londrina, V. 8, N. 4, Ed. 253, Art. 1676, Fevereiro, 2014.

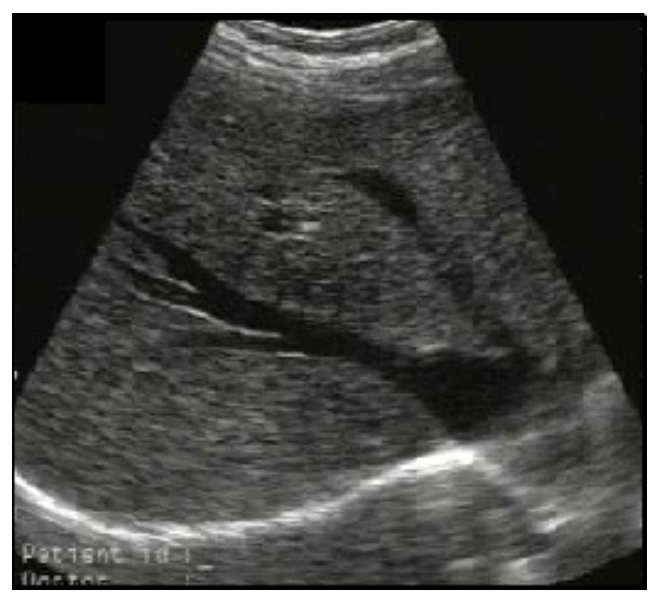

FIGURA 8 - Imagem do fígado. Transdutor em arranjo curvo mostrando um formato setorial.

Fonte: Adaptado de FERNANDES (2012).

Os transdutores de arranjo anular contêm múltiplos elementos de forma anular, dispostos concentricamente aninhados um dentro do outro (como um alvo de tiro). Estes possibilitam a focalização concêntrica do feixe, o qual é produzido de forma cônica, reduzindo a espessura do setor e possibilitando a detecção e caracterização de estruturas menores. Apesar dos arranjos anulares, ao contrário dos outros anteriormente apresentados, possibilitarem a focalização no plano em elevação, estes não podem ser dirigidos eletronicamente (NYLAND \& MATTOON, 2004; MIDDLETON et al., 2005).

O arranjo bidimensional possui elementos de cristal empilhados tanto em colunas como em fileiras, possibilitando uma espessura de corte variável. Este apresenta focalização variável no plano em elevação (RUMACK et al., 2012).

As sondas intraluminares (transdutores pequenos) podem ser colocadas dentro da luz de várias estruturas corporais, podendo ser posicionados próximo ao órgão de interesse. Pode-se usar frequências mais altas e obterem-se imagens com maior resolução. No entanto, a profundidade 
DIAS, L.R.O. et al. Fundamentos da exploração ecográfica. Parte I: Princípios biofísicos. PUBVET, Londrina, V. 8, N. 4, Ed. 253, Art. 1676, Fevereiro, 2014.

de aquisição de imagens é limitada. Os transdutores mais usados são os endovaginais e endorretais. As sondas intra-arteriais são as mais recentes intraluminares (MIDDLETON et al., 2005; KREMKAU \& CHAPTER, 2006).

A seguir, serão demonstrados tipos de transdutores lineares e convexos (Figura 9).

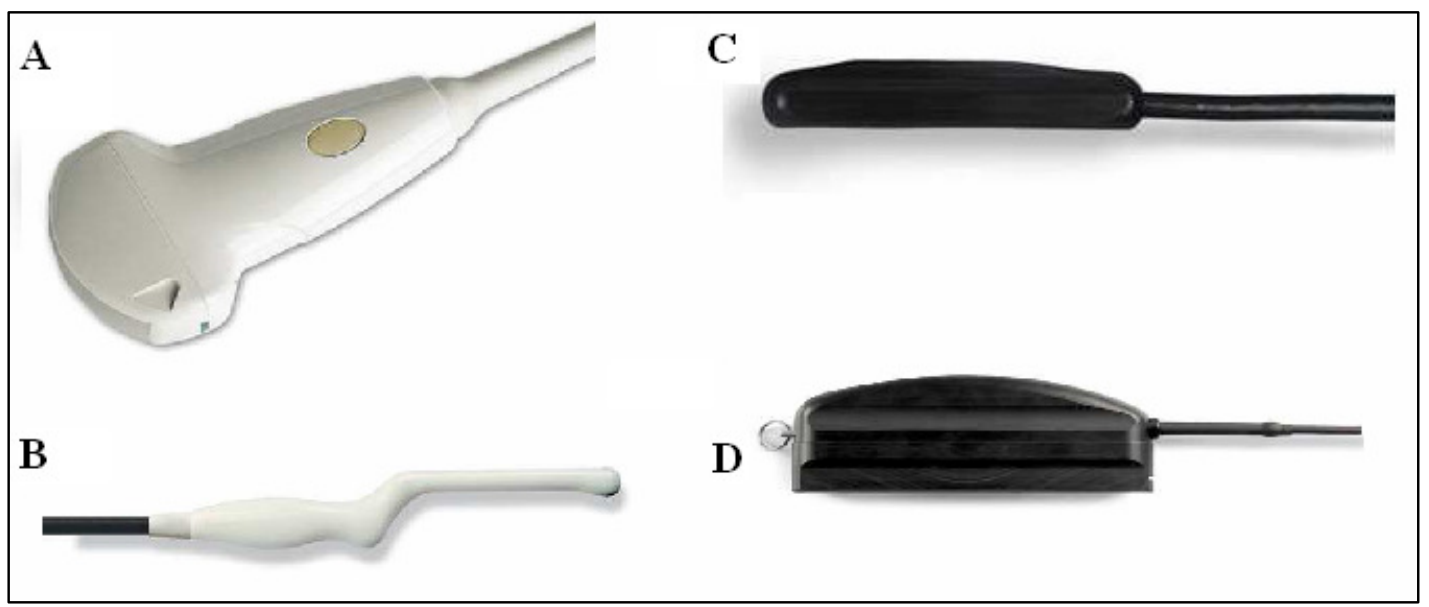

FIGURA 9 - Exemplo de transdutores. Em A, transdutor convexo. Em B, transdutor microconvexo. Em $\mathbf{C}$, transdutor linear. Em $\mathbf{D}$, transdutor linear setorial.

Fonte: Adaptado de FERNANDES (2012).

\section{Aquisição de imagens harmônicas}

As frequências harmônicas são produzidas com a passagem da onda sonora através dos tecidos e aumentam progressivamente em intensidade antes de diminuir devido à atenuação. $\mathrm{Na}$ aquisição dessas imagens, um filtro é usado para remover os ecos fundamentais (ruídos), onde somente o sinal de alta frequência seja processado para produzir uma imagem. Feixes harmônicos são mais estreitos que o feixe transmitido, assim ocorrerá melhora na resolução lateral, como é demonstrado na Figura 10 (LIEU, 2010; GUIMARÃES, 2007). 
DIAS, L.R.O. et al. Fundamentos da exploração ecográfica. Parte I: Princípios biofísicos.

PUBVET, Londrina, V. 8, N. 4, Ed. 253, Art. 1676, Fevereiro, 2014.
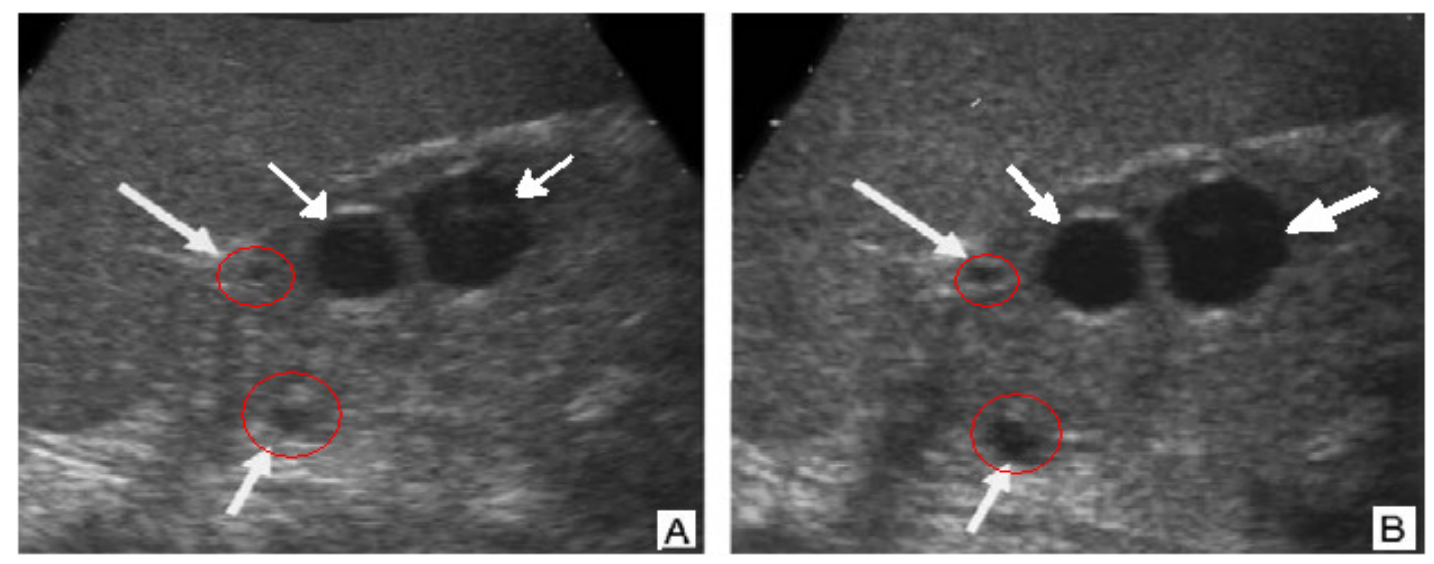

FIGURA 10 - Ecografia de rim policístico. Em A, imagem em modo B convencional. Em B, imagem harmônica de tecido, delineando melhor as bordas dos cistos. As setas brancas apontam as bordas dos cistos, os círculos vermelhos apontam os cistos menores.

Fonte: Adaptado de RICCABONA (2006).

\section{Aquisição de imagens ultrassonográficas tridimensionais}

O exame volumétrico estático ou tridimensional (3D) fundamenta-se na reconstrução digital de uma imagem bidimensional adquiridas por meio de transdutores multifrequenciais comuns (KURJAK et al., 2007; VERWOERDDIKKBOOM et al., 2010).

Segundo MIDDLETON et al. (2005), os dados para ultrassonografia 3D são adquiridos como uma pilha de cortes transversais paralelos, com o uso de um aparelho bidimensional, ou como um volume, usando uma sonda de arranjo eletrônico ou mecânico. As imagens 3D podem ser apresentadas em vários formatos, como a reformatação multiplanar, a visualização de volume e superfície e a endoscopia virtual. A aquisição dessas imagens também é possível na modalidade Doppler colorido. $O$ método 3D tem grande aplicação na avaliação da anatomia fetal, como demonstrado na Figura 11. 
DIAS, L.R.O. et al. Fundamentos da exploração ecográfica. Parte I: Princípios biofísicos.

PUBVET, Londrina, V. 8, N. 4, Ed. 253, Art. 1676, Fevereiro, 2014.

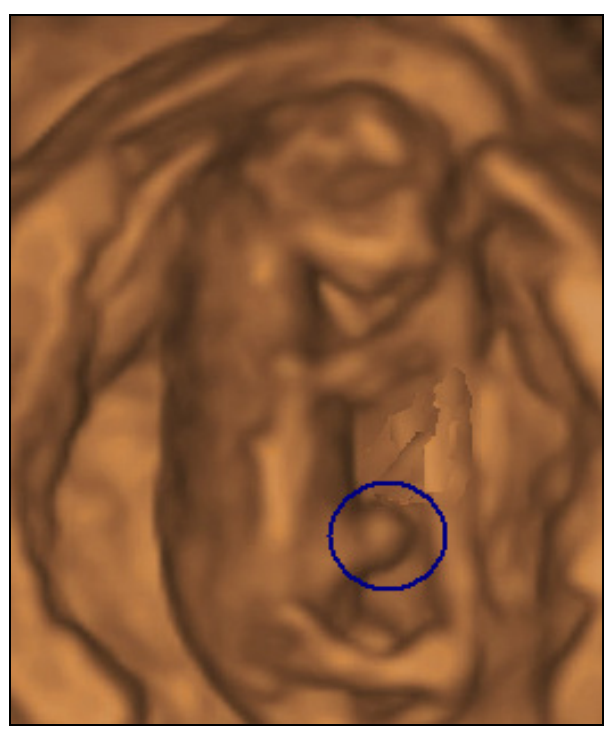

FIGURA 11 - Modo de superfície gerada com um transdutor micro-convexo (5 $9 \mathrm{MHz}$ ) mostrando um feto felino no $38^{\circ}$ dia pós-concepção. A imagem tridimensional mostra o feto embutido na placenta. A onfalocele fisiológica (circulada em azul) é notável nesta fase da gestação.

Fonte: Adaptado de HILDEBRANDT et al. (2009).

Os aparelhos modernos de ultrassom emitem uma imagem tridimensional do feixe que se diverge quando se propaga através do corpo. Quando eletronicamente lançados em várias sequências e padrões, os feixes coletivos gerados a partir de múltiplos elementos piezelétricos no transdutor irão produzir o feixe tridimensional (SITES et al., 2007).

Na Medicina Veterinária a utilização da técnica ecográfica 3D, por via transretal, forneceria informações valiosas quanto ao ovário e ao desenvolvimento fetal em animais de produção, tendo em vista uma interface que produz menos artefatos de imagem. No entanto, o custo do equipamento e a utilização de transdutores especiais desencorajam os profissionais a investir nessa tecnologia, limitando a sua aplicação em pesquisas (HILDEBRANDT et al., 2006; LUEDERS et al., 2009). 
DIAS, L.R.O. et al. Fundamentos da exploração ecográfica. Parte I: Princípios biofísicos. PUBVET, Londrina, V. 8, N. 4, Ed. 253, Art. 1676, Fevereiro, 2014.

\section{Otimização de imagens em escala de cinza}

\section{Vazão de Potência}

Determina a potência do pulso ultrassonográfico que é transmitido. Quando o pulso transmitido é mais forte, os ecos de retorno são mais fortes e a imagem decorrente disso terá mais brilho. A vazão de potência deve ser aumentada quando a atenuação (enfraquecimento das ondas sonoras à medida que se propagam nos tecidos) do som limitar a penetração e não se conseguir obter informações diagnósticas nem após o ajuste correto do ganho e da frequência do transdutor. Caso contrário deve-se usar níveis de potência previamente programados. Em todas as situações é prudente limitar-se ao máximo possível a potência usada e o tempo de exame, uma vez que o uso do equipamento com o ajuste da vazão de potência aumentado pode ocasionar diminuição da vida útil aparelho. Além disso, deve-se escolher a menor potência possível para se obter melhor resolução e prevenir a ocorrência de artefatos (NYLAND \& MATTOON, 2004).

\section{Ganho}

Devido à atenuação do som, uma interface nos tecidos profundos vai produzir um reflexo mais fraco e uma distorção menor dos elementos de cristal da sonda. Para compensar este efeito, os sinais de tecidos mais profundos são ampliados eletronicamente depois de retornarem ao transdutor. Como a profundidade da interface é determinada pelo tempo gasto para o pulso sonoro transmitido retornar ao transdutor, essa ampliação variável é designada como compensação do ganho temporal. O nível de ganho é mostrado ao lado da imagem, sob a forma de uma linha ou curva e deve ser ajustado para obter-se a imagem de aspecto cinzento uniforme (LIEU, 2010). Segundo NYLAND \& MATTOON (2004), quando se utiliza a menor potência obtém-se melhor resolução, além de prevenir a ocorrência de artefatos. 
DIAS, L.R.O. et al. Fundamentos da exploração ecográfica. Parte I: Princípios biofísicos. PUBVET, Londrina, V. 8, N. 4, Ed. 253, Art. 1676, Fevereiro, 2014.

\section{Zona Focal}

Com o uso de transdutores de arranjo eletrônicos é possível focalizar o som transmitido a profundidades diferentes. Esse controle também é designado como zona de transmissão e é geralmente indicado ao lado da imagem como uma ponta de seta. Ao examinar uma estrutura específica, a zona focal deve ser colocada no nível de interesse. Quando necessário é possível criar imagens separadas usando-se zonas focais em múltiplos níveis e "colar-se" essas partes para criar uma imagem complexa. A desvantagem pela focalização em múltiplos níveis é uma diminuição na frequência dos quadros (LIEU, 2010).

\section{Campo de Visão}

O campo de visão de uma imagem em tempo real pode ser dividido em profundidade e diâmetro. A desvantagem pelo aumento da profundidade ou do diâmetro é mostrada na imagem como centímetros ou como uma escala ao lado da imagem. O diâmetro é ajustado comumente com o uso de submenus (STAFFORD \& WHITMAN, 2011). Segundo LIEU (2010), a resolução lateral é pior nos campos próximo e distante, pois o feixe é mais amplo nessas regiões.

\section{Densidade de Linhas}

Cada imagem é constituída de múltiplas linhas de varredura adjacentes. A densidade das linhas de varredura pode ser ajustada para arranjos lineares (linhas de varredura por centímetro) e também para arranjos de fase e arranjos curvos (linhas de varredura por grau) (ALDRICH, 2007). Aumentar a densidade de linhas vai diminuir o tamanho dos pixels e melhorar a resolução da imagem (LIEU, 2010).

\section{Curvas da Escala Cinza}

Cada pixel numa imagem ultrassonográfica tem uma amplitude de eco designada, dependendo da potência dos reflexos desse pixel. A maneira 
DIAS, L.R.O. et al. Fundamentos da exploração ecográfica. Parte I: Princípios biofísicos. PUBVET, Londrina, V. 8, N. 4, Ed. 253, Art. 1676, Fevereiro, 2014.

exata pela qual os valores em escala de cinza são colocados em equivalência a amplitudes de eco pode ser variada, alterando-se as curvas da escala de cinza. A alteração destas curvas pode enfatizar diferentes aspectos da imagem ultrassonográfica. Por exemplo, pode-se atribuir a todos os ecos de amplitude baixa por um valor de preto e o resto da gama de valores da escala de cinza pode ser espalhado entre as amplitudes de eco elevadas. Há geralmente cinco a dez curvas para se escolher. A curva da escala de cinza usada é frequentemente mostrada na imagem pela letra " $C$ ", seguida do número da curva (MIDDLETON et al., 2005).

\section{Alcance Dinâmico}

O alcance dinâmico designa a gama de potência de sinal que pode ser efetivamente manejada pelo operador. Como o alcance é maior para o amplificador que para o monitor, os sinais recebidos devem ser comprimidos para poderem ser mostrados (LIEU, 2010).

\section{Persistência}

Segundo STAFFORD \& WHITMAN (2011), persistência é a abordagem tradicional para reduzir os ruídos no ultrassom. Esta técnica se baseia em movimento ou fluxo entre pontos de manchas de líquido e, assim, reduzi-las pela média de vários quadros juntos. Pequenas diferenças entre quadros devido ao movimento provocado pelo operador ou o movimento do tecido conduzem a uma redução na manchas.

\section{Sonografia pelo Doppler}

A ferramenta Doppler associada à ultrassonografia convencional proporciona informações em tempo real sobre a arquitetura vascular e os aspectos hemodinâmicos dos vasos em diversos órgãos. Devido ao efeito do Doppler, os sons que se refletem num objeto em movimento sofrem uma mudança de frequência. Assim, objetos que se movem em direção oposta ao transdutor refletem o som a uma frequência mais baixa do que a do pulso 
DIAS, L.R.O. et al. Fundamentos da exploração ecográfica. Parte I: Princípios biofísicos. PUBVET, Londrina, V. 8, N. 4, Ed. 253, Art. 1676, Fevereiro, 2014.

incidente. Já objetos que se movem em direção ao transdutor refletem o som a uma frequência mais alta. Essa diferença entre a frequência transmitida e a recebida é dada como desvio de frequência do Doppler (ALDRICH, 2007; CARVALHO et al., 2008). A magnitude desse desvio é determinada pela equação:

\section{Fd $=$ Ft $-F r=2 \times F t \times(V / C) \times \cos \theta$}

Onde: $\mathrm{Fd}=$ desvio da frequência do Doppler, $\mathrm{Ft}=$ frequência transmitida, $\mathrm{Fr}=$ frequência recebida, $V=$ velocidade do alvo em movimento, $c=$ velocidade do som nos tecidos moles e $\theta$ o ângulo entre a direção do fluxo sanguíneo e a direção do pulso sonoro transmitido (MIDDLETON et al., 2005).

\section{Doppler Pulsátil}

O aparelho Doppler pulsátil transmite curtos pulsos em intervalos regulares e recebe o sinal refletido no resto do tempo, comparando-o com aquele transmitido. A onda pulsada permite ao Doppler medir uma região específica dentro de um campo de imagem, possibilitando assim a medida da velocidade dentro dos vasos selecionados. A frequência com a qual os pulsos são emitidos por segundo é chamada de frequência de repetição de pulso (FRP). O tempo entre o pulso e o eco depende do local de reflexão, embora seja possível localizar a fonte do eco retornado. A região onde os sinais Doppler são mensurados é chamada de volume de amostra ou portal Doppler (CARVALHO et al., 2008; CHAMMAS \& CERRI, 2009; COLTRERA, 2010).

A posição do volume de amostra pode ser ajustada, obtendo-se sinais de vasos específicos através do uso de uma imagem em escala de cinza padrão para se visualizar os vasos de interesse. Essa combinação é designada como sonografia do Doppler Duplex (ALDRICH, 2007).

De acordo com o indicado na equação do Doppler, o desvio da frequência é proporcional à velocidade e também ao $\cos \theta$. Assim, ao orientarse o pulso do Doppler transmitido em direção ao fluxo sanguíneo de modo que o ângulo do Doppler fique o mais próximo de $0^{\circ}$ o maior sinal do Doppler será 
DIAS, L.R.O. et al. Fundamentos da exploração ecográfica. Parte I: Princípios biofísicos. PUBVET, Londrina, V. 8, N. 4, Ed. 253, Art. 1676, Fevereiro, 2014.

obtido. Uma vez que num ângulo a $0^{\circ}$, onde fluxo sanguíneo e a direção do som são paralelos, o $\cos \theta$ é igual a 1 ; (valor máximo possível para o $\cos \theta$ ) (MIDDLETON et al., 2005; LIEU, 2010).

\section{Doppler Colorido}

No Doppler colorido o deslocamento de frequência Doppler é demonstrado como um espectro de uma ou duas cores dentro de uma área definida (caixa colorida) (CARVALHO et al., 2008).

A sonografia pelo Doppler colorido fornece uma imagem em tempo real, mostrando a morfologia tecidual em escala cinza e o fluxo sanguíneo a cores. São analisadas informações de fase, frequência e amplitude dos ecos de retorno. Os sinais de hemácias em movimento têm uma cor a eles atribuída (vermelho versus azul), com base na direção do desvio de fase, como é demonstrado na Figura 12. Esta técnica permite avaliar a presença, a direção e a qualidade do fluxo sanguíneo mais rapidamente do que qualquer outra técnica não invasiva. Além disso, é possível a diferenciação entre fluxos rápidos e lentos (CARVALHO et al., 2008; COLTRERA, 2010).

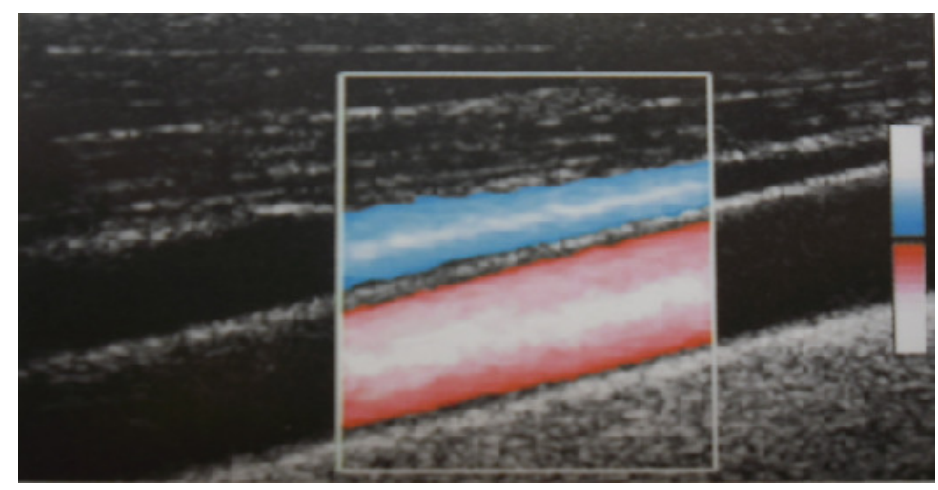

FIGURA 12 - Imagem do Doppler colorido da artéria carótida comum (vermelho) e da veia jugular interna (azul). O fluxo sanguíneo orientado em direção oposta ao pulso sonoro é mostrado em vermelho e o fluxo em direção ao pulso sonoro é mostrado em azul.

Fonte: adaptado de MIDDLETON et al. (2005). 
DIAS, L.R.O. et al. Fundamentos da exploração ecográfica. Parte I: Princípios biofísicos. PUBVET, Londrina, V. 8, N. 4, Ed. 253, Art. 1676, Fevereiro, 2014.

\section{Doppler de Potência}

O Doppler de potência avalia a potência ou força do sinal do Doppler. A potência do sinal não é afetada pelo ângulo Doppler. A cor e a nuance se relacionam ao volume sanguíneo e não à direção do fluxo ou à velocidade do fluxo (Figura 13). No visor desse Doppler atribui-se a um ruído de nível baixo um fundo colorido homogêneo, mesmo quando o ganho é muito aumentado, possibilitando o uso de ajustes de ganho mais altos e um aumento mínimo na sensibilidade ao fluxo sanguíneo. No entanto, essa categoria é muito suscetível ao artefato de flash (zonas de cor intensa que decorrem do movimento nos tecidos moles e do movimento do transdutor), permanecendo uma modalidade auxiliar (MIDDLETON et al., 2005; LIEU, 2010).

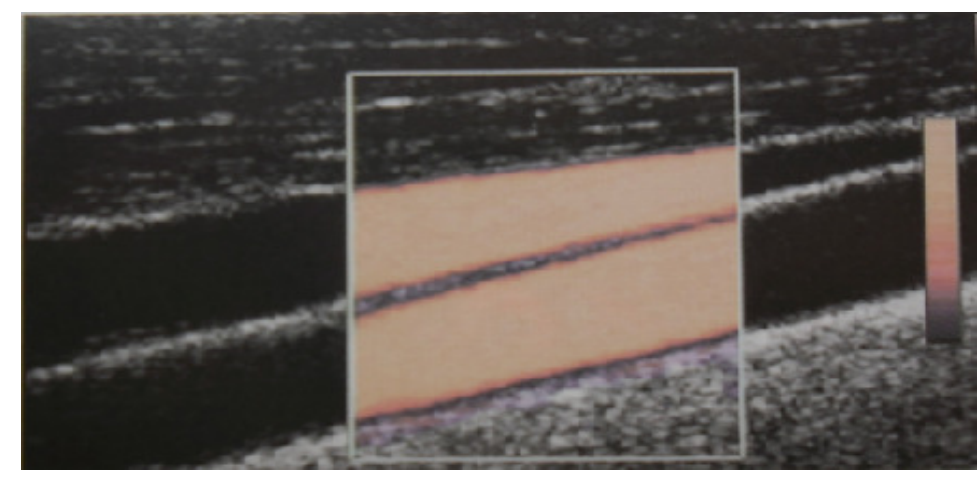

FIGURA 13 - Imagem do Doppler de potência da artéria carótida comum e da veia jugular interna. Informações sobre a direção e velocidade do fluxo não são mostradas nesses exames.

Fonte: adaptado de MIDDLETON et al. (2005).

\section{Otimização pelo Doppler}

Transdutores de frequência mais alta causam um desvio de frequência maior do Doppler. Essas sondas acarretam um reflexo mais forte vindo das hemácias, uma vez que a reflexão de objetos pequenos é proporcional à quarta frequência transmitida. Quando a detecção do fluxo num determinado vaso estiver difícil, é aconselhável usar-se várias sondas diferentes operando em frequências diferentes. Para aplicações superficiais, 
DIAS, L.R.O. et al. Fundamentos da exploração ecográfica. Parte I: Princípios biofísicos. PUBVET, Londrina, V. 8, N. 4, Ed. 253, Art. 1676, Fevereiro, 2014.

são recomendadas as sondas de frequência mais alta. Já para aplicações profundas recomenda-se o uso das sondas de frequência mais baixa (MIDDLETON et al., 2005).

Há uma diminuição progressiva na intensidade da onda sonora, causada pelo atrito com os diferentes tecidos. Para compensar essa diminuição utiliza-se o ganho, que é a amplificação dos ecos recebidos. O ganho é também chamado ganho de tempo de compensação. No modo de Doppler não é possível a amplificação parcial de sinais, quando o ganho é aumentado todos os ecos aumentam, inclusive o ruído. A imagem na tela será branca na forma homogênea, favorecendo os limites entre sinais de velocidade da onda do fluxo sanguíneo, já o ruído não é claramente distinguível. Se o ganho é muito baixo, alguns elementos do fluxo não se incorporam na onda e são excluídos da análise (CASTRO et al., 2007).

O débito de potência indica a potência do pulso ultrassonográfico transmitido. Os reflexos mais fortes são produzidos pelos pulsos sonoros mais fortes, sendo detectados mais facilmente. Assim, aumentando-se este débito melhora-se a sensibilidade do Doppler. Porém, com esse aumento a exposição do paciente também será maior, podendo causar vários artefatos (MIDDLETON et al., 2005).

A frequência de repetição de pulsos (FRP) indica o número de pulsos sonoros transmitidos por segundo. Essa frequência estando elevada acarreta uma alta escala do Doppler e, estando mais baixa, acarreta uma escala do Doppler mais baixa. No entanto, ao ajustar-se a escala do Doppler a FRP é mudada. Se a escala do Doppler estiver alta, a visualização de um fluxo em alta velocidade não apresentará artefatos de interrupção. A escala do Doppler estando baixa haverá melhor sensibilidade a um fluxo sanguíneo a baixa velocidade (CHAMMAS \& CERRI, 2009).

Para melhorar a sensibilidade do Doppler também se pode aumentar o número de pulsos sonoros usados para gerar cada linha individual de informação do Doppler colorido, sendo esse controle designado como extensão do conjunto, tempo de duração ou sensibilidade a cores. Quando mais pulsos 
DIAS, L.R.O. et al. Fundamentos da exploração ecográfica. Parte I: Princípios biofísicos. PUBVET, Londrina, V. 8, N. 4, Ed. 253, Art. 1676, Fevereiro, 2014.

são usados, a detecção dos desvios de frequência numa determinada localização é mais fácil. No entanto, usando-se mais pulsos por linha, necessita-se de mais tempo pra geração dos quadros do Doppler colorido individual, diminuindo a frequência dos quadros (MIDDLETON et al., 2005).

O filtro analisa os sinais de intensidade acima ou abaixo de um determinado nível. Assim, o movimento tecidual que pode atrapalhar o sinal pode ser reduzido ou eliminado (CASTRO et al., 2007). CHAMMAS \& CERRI (2009) recomendam a utilização da menor filtragem disponível no equipamento, evitando-se a eliminação de sinas de vasos com baixas velocidades.

Para eliminar informações de cores indesejadas pode-se estabelecer um valor da escala de cinza acima do qual as informações de cores são suprimidas. Qualquer atribuição de cores provenientes de um pixel que não seja anecoica ou muito hipoecoica deve ser um artefato. Quando a sensibilidade do Doppler não é adequada para a detecção do fluxo, a prioridade de cores deve ser aumentada até seu valor máximo, para que nenhuma informação de cores esteja sendo suprimida (ALLAN, 2008).

O direcionamento do feixe é uma opção em transdutores de arranjo linear e ocorre automaticamente em sondas em arranjo de fase sempre que a aquisição de imagens do Doppler for efetuada nas bordas da imagem setorial. Ecos de retorno de um pulso dirigido atingem a superfície de um transdutor num ângulo e produzem um efeito menor sobre os cristais, além de um impulso eletrônico mais fraco que os ecos não dirigidos (MIDDLETON et al., 2005; CHAMMAS \& CERRI, 2009).

\section{CONSIDERAÇÕES FINAIS}

O emprego das técnicas ecográficas aqui apresentadas exige a ampliação dos conhecimentos do profissional que pretende utilizá-las, necessitando treinamento específico para cada modalidade. Além disso, conhecer os princípios da formação de imagem é de fundamental importância para o auxílio diagnóstico em Medicina Veterinária. 
DIAS, L.R.O. et al. Fundamentos da exploração ecográfica. Parte I: Princípios biofísicos. PUBVET, Londrina, V. 8, N. 4, Ed. 253, Art. 1676, Fevereiro, 2014.

O método pela ultrassonografia tridimensional se torna um desafio para os profissionais Médicos Veterinários, pois os equipamentos apresentam valores elevados e a colaboração do paciente animal poderia dificultar a aplicação dessa técnica.

Atualmente a tecnologia permite o uso da telemedicina através da realização de ações médicas à distância. Assim, a interação entre os profissionais da área de ecografia, buscando instituições de referência para o auxílio diagnóstico, facilitaria a interpretação de exames ultrassonográficos, acarretando redução de tempo e custos para realização de exames individuais de pacientes.

\section{REFERÊNCIAS}

ALDRICH, J. E. Basic physics of ultrasound imaging. Critical Care Medicine, Baltimore, v. 35, n. 5, p. 131-137, 2007.

ALLAN, P. L. P. Ultra-sonografia com Doppler na prática Clínica. $2^{a}$ ed. São Paulo: Elsevier Brasil, 2008, 384p.

CARVALHO C. F. Ultrassonografia em pequenos animais. $1^{\text {a }}$ ed. São Paulo: Roca, 2004, 384p.

CARVALHO C. F., CHAMMAS M. C., CERRI G. G. Princípios físicos do Doppler em ultrassonografia. Ciência Rural, Santa Maria, v. 38, n. 3, p. 872-879, 2008.

CAstro, N. M.; Álvarez, Ó. M.; HUertA, M. G.; ANDRADE, É. H. Principios físicos, metodología, consistencia y seguridad del ultrasonido Doppler en la evaluación fetoplacentaria. Ginecología y Obstetricia de México, México, v. 75, n. 10, p. 621-9, 2007.

CHAMMAS M. C.; CERRI, G. C.Ultrassonografia abdominal. $2^{\text {a }}$ ed. Rio de Janeiro: Revinter, 2009, 618p.

COLTRERA, M. D. Ultrasound physics in a Nutshell. Otolaryngologic Clinics of North America, Philadelphia, v. 43, n. 6, p. 1149-1159, 2010.

CRUZ, J. F.; FREITAS, V. J. Ultrassonografia em tempo real na reprodução de caprinos. Ciência Rural, Santa Maria, v. 11, n. 1, p. 45-53, 2001.

DROST, W.T. Basic ultrasound physics. In: THRALL, D.E. Textbook of veterinary diagnostic radiology. $5^{a}$.ed. Philadelphia: Saunders Elsevier, cap.2, 2007, p. 38-49.

FERNANDES, C. A. C. Ultrassonografia em Reprodução de Bovinos. [Apostila] Agripoint, 2012, $171 \mathrm{p}$. 
FISCHETTI, A. J.; SCOTT, R. C. Basic ultrasound beam formation and instrumentation. Clinical Techniques in Small Animal Practice, Philadelphia, v. 22, n. 3, p. 90-92, 2007.

GUIMARÃES, I. F. Tomada de decisão com múltiplos critérios na seleção de equipamento médico-hospitalar. 2007. 147 f. Dissertação (Mestrado em Ciências em Engenharia de Produção) Pós-Graduação em Engenharia de Produção) - Programa de PósGraduação em Engenharia De Produção, Universidade Federal De Itajubá, Itajubá - MG.

HAGEN, S. Bases físicas da ultrassonografia e introdução á aplicação clínica em equinos. [Artigo online]. 2009. Disponível em: http:www.equalli.com.br/upload/textos/pdf/prt/48.pdf. Acessado em 05 de novembro 2012.

HILDEBRANDT, T. B.; GÖRITZ, F.; HERMES, R. Ultrasongraphy: an important tool in captive breeding management in elephants and rhinoceroses. European journal of wildlife research, Londres, v. 52, n. 1, p. 23- 27, 2006.

HILDEBRANDT, T. B.; DREWS, B.; KURZ, J.; HERMES, R.; YANG, S.;GÖRITZ, F. Pregnancy monitoring in dogs and cats using $3 \mathrm{D}$ and $4 \mathrm{D}$ ultrasonography. Journal of reproduction of domestic animals, Nova York, v. 44, supp. 2, p. 125-128, 2009.

JAINUDEEN, M. R.; HAFEZ, E. S. E. Diagnóstico da gestação. In: HAFEZ, B.; HAFEZ, E. S. E. Reprodução animal. 7a ed. Barueri, São Paulo: Manole, 2004, p.399-408.

KEALY, J. K.; MCALLISTER, H. Radiologia e ultrassonografia do cão e do gato. $3^{a}$ ed. São Paulo: Manole, 2005, 436p.

KREMKAU, F. W.; CHAPTER, L.. Diagnostic Ultrasound, Principles and Instruments. 7a ed. Editora Saundres Elsevier:St. Louis, 2006, 590 p.

KIMURA, J. P. E.; COSTA, E. T. Programa código aberto para a formação de imagens por ultrassom. São Paulo: IFMBE, 2007, p. 588-597.

KURJAK, A; MISKOVIC, B; ANDONOTOPO, W; STANOJEVIC, M; AZUMENDI, G; VRCIC, H. HOW useful is $3 D$ and $4 D$ ultrasound in perinatal medicine? Journal of perinatal medicine, Berlin, v. 35, n. 1, p. 10-27, 2007.

LIEU, D. Ultrasound Physics and Instrumentation for Pathologists. Archives of Pathology \& Laboratory Medicine. Chicago, v. 134, n. 10, p. 1541-1556, 2010.

LUeders, I.; NIEMUlleR, C.; POOTOOLAL, J.; RICH, P.; GRAY, C.; STREICH, W. J.; HILDEBRANDT, T. B. Sonomorphology of the reproductive tract in male and pregnant and nonpregnant female Rothschild's giraffes (Giraffa camelopardalis rotschildi). Theriogenology, San Diego, v. 72, n. 1, p. 22- 31, 2009.

MIDDLETON, W. D.; KURTZ A. B.; HERTZBERG B. S. Ultra-som: os requisitos, $2^{\text {a }}$ ed., Rio de Janeiro: Elsevier, 2005, 608p.

NEVES, J. P.; OLIVEIRA, J. F. C.; FREITAS V. J. F.; Simplício A. A.; TEIXEIRA D. I. A.; ALMEIDA J. L. Diagnóstico de Prenhez nos Ruminantes. In: GONÇALVES, P. B. D.; FIGUEIREDO, J. R.; FREITAS, V. J. Biotécnicas Aplicadas à Reprodução Animal. $2^{\text {a }}$ ed., São Paulo: Roca, 2008, cap.2, p.17-32.

NYLAND, T. G.; MATTOON, J. S. Ultrassom diagnóstico em pequenos animais. $2^{a}$ ed. São Paulo: Roca, 2004, 506p. 
RICCABONA, M. Modern pediatric ultrasound: potential applications and clinical significance: A review. Journal of Clinical Imaging, Mumbai, v. 30, n. 2, p. $77-86,2006$.

RUMACK, C. M.; WILSON, S. R.; CHARBONEAU, J. W. Tratado de Ultrassonografia Diagnóstica, $4^{\mathrm{a}}$ ed. Rio de Janeiro: Elsevier, 2012, 2200p.

SANTANA, V. J. Modelagem de transdutores de ultra-som de alta frequencia com arranjo em anel. 2008. 85f. Dissertação (Pós-Graduação em Tecnologia) - Programa de PósGraduação em Tecnologia, Centro Federal de Educação Tecnológica Celso Suckow da Fonseca, CEFET - RJ.

SIMÕES, J. Os princípios físicos, a imagem e os artefatos na ecografia em modo-B. [Apostila online] $\quad v$. $1, \quad n$ n $1, \quad 2008 . \quad$ Disponível em: http://www.veterinaria.com.pt/media//DIR_27001/VCP1-1-e22.pdf. Acessado em 21 de novembro 2012.

SITES, B. D.; BRULL, R.; CHAN, V. W. S.; SPENCE, B. C.; GALLAGHER, J.; BEACH, M. L.; SITES, V. R.; HARTMAN, G. S. Artifacts and Pitfall Errors Associated With Ultrasound-Guided Regional Anesthesia. Part I: Understanding the Basic Principles of Ultrasound Physics and Machine Operations. Regional Anesthesia and Pain Medicine. Secaucus, v. 32, n. 5, p. 412-418, 2007.

STAFFORD, R. J.; WHITMAN, G. J. Ultrasound Physics and Technology in Breast Imaging. Ultrasound Clinics, v. 6, n. 3, p. 299-312, 2011.

VARGAS, A.; AMESCUA-GUERRA, L. M.; BERNAL, M. A., PINEDA, C. Principios físicos básicos del ultrasonido, sonoanatomía del sistema músculo esquelético y artefactos ecográficos. Acta Ortopédica Mexicana, México, v.22, n. 6, p. 361-373, 2008.

VERWOERD-DIKKEBOOM, C. M.; KONING, A. H. J.; HOP, W. C. VAN DER SPEK, P. J.; EXALTO, N.; STEEGERS, E. A. P. Innovative virtual reality measurements for embryonic growth and development. Human Reproduction, Londres, v. 25, n. 6, p. 1404-1410, 2010.

VESCOVI, L. A.; MONTEIRO, J. N. M. SANTOS, W. G.; OliVEIRA, D. C.; BORLIN, D. C.; MACHADO, F. M.; MARTINS FILHO, S.; COSTA, F. S. Ultrassonografia quantitativa do baço de gatos normais. Veterinária em foco, Canoas, v. 7, n. 1, p. 4-10, 2009. 